\title{
Article \\ Development of a Steel Plant Rescheduling Algorithm Based on Batch Decisions
}

\author{
David García-Menéndez, Henar Morán-Palacios *, Eliseo P. Vergara-González and Vicente Rodríguez-Montequín (D)
}

check for

updates

Citation: García-Menéndez, D.;

Morán-Palacios, H.;

Vergara-González, E.P.;

Rodríguez-Montequín, V.

Development of a Steel Plant

Rescheduling Algorithm Based on Batch Decisions. Appl. Sci. 2021, 11, 6765. https://doi.org/10.3390/ app11156765

Academic Editors: Dimitris Mourtzis and Paolo Renna

Received: 27 April 2021

Accepted: 20 July 2021

Published: 23 July 2021

Publisher's Note: MDPI stays neutral with regard to jurisdictional claims in published maps and institutional affiliations.

Copyright: (c) 2021 by the authors. Licensee MDPI, Basel, Switzerland. This article is an open access article distributed under the terms and conditions of the Creative Commons Attribution (CC BY) license (https:// creativecommons.org/licenses/by/ $4.0 /)$.
Project Engineering Area, University of Oviedo, 33004 Oviedo, Spain; davidbelenos@gmail.com (D.G.-M.); vergaraeliseo@uniovi.es (E.P.V.-G.); montequi@api.uniovi.es (V.R.-M.)

* Correspondence: henar.moran@api.uniovi.es; Tel.: +34-985-104-272

Featured Application: The current paper presents a newly designed algorithm to optimize continuous casting productions in the case of loss on strands during casting.

Abstract: During the steelmaking and continuous casting process in the steel plant, it is common to encounter delays that affect initial planning. Furthermore, continuous casting machines themselves can lose much of their performance in the event of closure of one or more of their casting strands. The situation that is generated, far from being a planning problem, forces consideration of a vision of cost analysis when deciding changes in the planned sequences. This study presents a detailed analysis of the different circumstances that can cause strands closures or sequence breaks, their consequences and the different options available to minimize losses. Finally, an algorithm capable of analyzing the workshop situation and making the most favorable decision to optimize production is proposed, analyzed and compared with the efficiency of the original scheduling method in a real steel plant. The new algorithm proves its efficiency in all situations, with a time-saving average of $26.41 \mathrm{~min}$ per decision taken.

Keywords: scheduling; casting scheduling problem; steelmaking and continuous casting; production planning

\section{Introduction}

The iron and steel industry is one of the largest industries in the world economy, and supplies materials to construction, machinery, automotive and other industries [1]. The steel plant represents the critical process of the steel industry, processing pig iron and achieving a chemical composition that defines the grade of steel wanted to be achieved. Modern integrated mills comprise a steel manufacturing process ranging from the conversion of cast iron into steel in converters or a basic oxygen furnace (BOF), to its final casting in the continuous casting machine (CC), through refining in secondary metallurgy (SM) [2-4]. The process followed by this type of steelworks is known as steelmaking continuous casting (SCC), and is mainly divided into three phases: steelmaking, refining and continuous casting [5].

The first phase is the steelmaking phase. This process is carried out in converters (BOF, Basic Oxigen Furnace), in which the pig iron obtained from the blast furnace is reduced to eliminate impurities. The second phase is the secondary metallurgy, or ladle metallurgy, and is a set of processes and operations whose objective is to transform the liquid steel of the converter into a liquid adjusted to solidify, having three main objectives: adjust the heat in composition; minimize the composition of non-metallic impurities and adjust the temperature of the heat. This phase takes place in different stations as the ladle furnace (LD) or the degassing station (RH [5]). Finally, the last phase is the continuous casting process (CC); this is the process whereby the melt is poured into a bottomless mold whose cross section has the geometric shape of the semi-finished product to be manufactured. The liquid steel is poured directly into a bottomless mold with the shape of the cross section of 
the semi-finished product to be manufactured, as already stated. It is called continuous because the liquid steel reaches the mold without interruption, being able to work without stopping the line [6]. Unlike conventional casting, semi-finished products are obtained directly from this procedure, without having to go through a pit furnace and a roughing train again [5].Cast refers to the sequence of consecutive heats loaded into the CC machine, and could be also known as tundish, as the vessel through which molten metal flows before solidifying in the continuous casting mold [7].

The semi-finished products obtained are rectangular flat slabs (blooms) or square section (slabs and billets). A typical steelmaking continuous casting process is represented in Figure 1, where the three phases of the process are shown and the different semiproducts displayed.

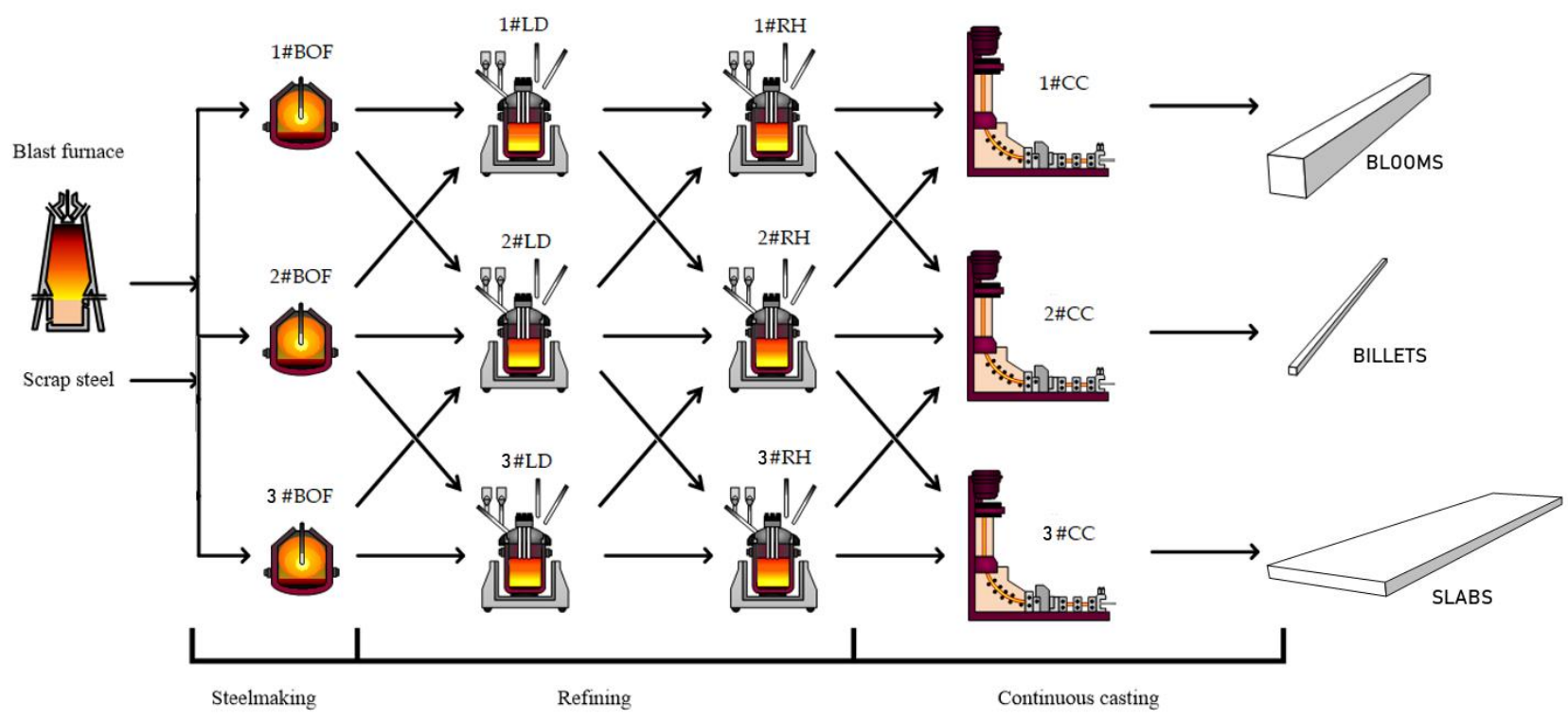

Figure 1. Phases of a typical Steelmaking Continuous Casting process.

These are three types of semi-products, and each one is obtained in a different machine. Due to the dimensions of the product obtained, Slab casting machines have two simultaneous casting lines or strands, bloom casters three or four, and billet casters up to six or eight $[8,9]$.

Typically, the steel mill is the production bottleneck in the steel industry, and therefore proper scheduling of steel works is crucial to improve overall production [10-12]. Steel mill production scheduling is considered one of the most complicated problems of production scheduling, as it comprises several stages and multiple restrictions, with increasing demands of product variability [13]. For years, various optimized models have been studied [14,15] and approaches capable of considering limited machine availability [16], different casting speed $[17,18]$ or job cancellations are taken into account.

In actual steel plants, unforeseen events such as sequence cuts or job cancellations may occur, requiring the original deterministic production plan to be revised $[19,20]$. Due to this, the development of rescheduling has become essential, either repairing the original schedule or generating again an optimal schedule [21]. Thus, algorithms have been developed that allow approaching the problem of scheduling with different interruptions [22], algorithms that allow dealing with the machine's setup times [23], jobs with specific routes that avoid some steps $[24,25]$, multi-criteria algorithm methods $[26,27]$ and even algorithms that consider several sources of interruption simultaneously (job variation, job cancellation, job time variation, machine breakdown and new jobs) [28-33]. Industry 4.0 and smart manufacturing [13] are also capable of creating a virtual copy of the physical world and make decentralized decisions [34], so new approaches can be seen based on decision-making schema [20] or adaptative scheduling [35]. 
However, despite these advances, it is common that a manual rescheduling takes place, minimizing the loss of time in the workshop [36]. The main reason for this manual rescheduling is the faster human reaction to unexpected events [37], based on their understanding and knowledge of past experiences. Furthermore, in real environments, the problems that arise are random and dynamic, so the parameters, limitations, and objectives change over time [38]. In general, the different contingencies in steelmaking production can be divided into three classes [39]. Firstly, there are contingencies that are resource related [40], such as the shortage of raw material, a lack of adequate personnel to carry out the necessary tasks or even machine breakdowns. Then, there are eventualities that are job related, such as the interruptions or cancelations of jobs, or changes in process or transport time. Finally, some contingencies are both resource and job related, such as a lack of energy or quality problems.

One of the last problems to be solved in planning has to do with the performance of continuous casting machines and the optimization of the production process [41]. A common problem in modern steel mills is the loss of one of the continuous casting strands during casting, due to three main reasons: first, castability, deposition of material in the nozzles that prevents the passage of steel into the mold. Second, cold steel, causing the solidification of the steel itself, sealing the nozzle. Last, perforation/breakout of the liquid metal, which happens when the solid shell of the strand breaks and allows the still-molten metal contained within to spill out and foul the machine. These problems imply a loss of time during the continuous casting phase, and therefore a loss of productivity. In current planning, such losses are assumed as delays in the casting machine [42].

Scheduling in a steel plant is one of the most complicated problems of industrial organization. The steel mill is a living work environment where a multitude of unforeseen events that affect production can arise, whether they are operational efficiency, environmental parameters, job cancellations [42,43], resource constrains [44] or others.

In a simplified way, any contingency can be considered a trigger for a machine stop, but reality indicates that sometimes it simply affects the casting speed, or the closure of any of the lines. Some studies consider the casting time as a variable that allows optimizing the process time, avoiding sequence breaks. Most of the approaches do not contemplate these unforeseen events, assuming delays and generating new schedules based on the original parameters, due to the static characteristics of these schedules [45].

The scheduling problems have already been classified according to different criteria [46], including, mainly, two types of decisions [6].

- Batch decisions, in which the primary requirements of orders are transformed into production batches. There are two types of batches in steel mill production. One is called heat and the other is cast or tundish.

- Scheduling decisions, i.e., allocation, sequencing and timing of heats and casts in the relevant facilities, from steel fabrication to continuous casting production, including intermediate treatments.

The first decisions, or batch problems, are based on prioritizing the primacies of the different steels in order to carry out a product-client scheduling. Once these works are organized, a medium-term production plan, or master production schedule (MPS), is obtained. After that, the scheduling is carried out with batch restrictions in a second phase, and therefore certain parameters established in the planning are immovable. The SCC scheduling problem can be considered as a hybrid flow shop (HFS) scheduling problem where there are batching constraints in the last stage [1]. The development of static, simplified models, which consider a large part of the variables as immutable over time, has been studied from multiple approaches. However, during scheduling in a real environment, many more parameters are subject to variability, including multiple constraints and changing objectives over time $[38,47,48]$. The great variety of solutions provided by different researchers corresponds to the numerous and disparate simplifications that are carried out in the development of formulations, and the different ways in which they face the various unforeseen events that may happen during the development of planning. 
When looking for optimal planning for improved steel plant production, the type of methodologies that should be considered, as they are the most advantageous, are those mixed methodologies, in which algorithms and programming systems are used under human supervision [26,49]. Normally, the decision on the method to apply is not carried out by the scheduling algorithm, but by the coordinator or plant manager [11,50-52].

After any unexpected event that leads to the closure of lines or strands, some of the actions that can be taken to minimize losses are in direct conflict not only with the scheduling decisions but also with the batch decisions chosen previously, so an optimization of the production will go through not only a modification of the rescheduling but also the MPS as well.

Due to this, the objective of this research is the development of an algorithm capable of recognizing the comprehensive knowledge of the operation of the steelworks and generating a model of programming decisions in continuous casting, modifying the MPS. In this study, the impact that line losses can have on modern steel mills is considered and the ways to mitigate or reduce that impact is studied. For this, an algorithm is proposed, so that production is optimized, using various tools beyond job reordering. Then, an extensive simulation was performed to check the validity of the algorithm. Finally, a comparison was made between the losses generated by an event involving losses of lines in continuous casting, between a standard MPS and one obtained with the developed algorithm.

\section{Method}

In order to minimize the losses caused by the closure of any strand of the continuous casting machine, the initial scheduling must be recalculated, and the decision batches must be adapted to the workshop situation. Most of the currently used algorithms focus on the scheduling decisions, avoiding the possibility of rearranging the heats according a new and more suitable planning of the required batches. Therefore, an algorithm was developed, capable of comparing the different scheduling that can be performed from a trigger event that lead to close of one or several lines, even changing the batch decisions, in order to improve productivity on the steel plant.

For this, the decision tree technique was applied. Therefore, bearing in mind that the scenario takes place in a steel plant, various possible final cases were reached by analyzing a series of assumptions that involved a succession of decisions. That is, from the initial scheduling, the implications of the line loss in the scheduling itself were analyzed in detail, as well as the different routes that can be generated when recalculating it. These were compared in such a way that adequate decision-making can be carried out depending on new situation of the steel plant. Each one of the routes is equivalent to the adaptation of a batch decision in a particular way, considering all the possible cases that can be carried out. This involves a detailed analysis of all the available routes allowed to make a comparison and work out the appropriate decision making.

Any change in the MPS that affects heats or tundish that have not yet entered the production process can be programmed in an optimal way, while those that are already in process may suffer the restrictions of the current state of the factory, or its own quality conditions. That is why the algorithm focuses on the decisions to be made for these washes that have already entered the production cycle; that is, they have already been dealt with in the converter. For the experimental evaluation, a typical steel mill has been taken as a model, with two different casting machines, two ladle furnaces and two converters, in which at any time, the maximum number of castings in process is four, this being the number of steps that the decision tree will advance, from heat $\mathrm{N}$, where the disruptive event occurs, to heat $\mathrm{N}+3$.

Figure 2 shows the schematic of the algorithm's decision tree. These decisions were made following the loss of one or more lines in the casting machine, due to a trigger event. It was observed that for each of the heats scheduled, four different options can be chosen:

1. Cast the heat, following the sequence;

2. Return the heat to converter; 
3. Reapply the heat to a different quality;

4. Rearm the machine and cast the heat by starting a new sequence.

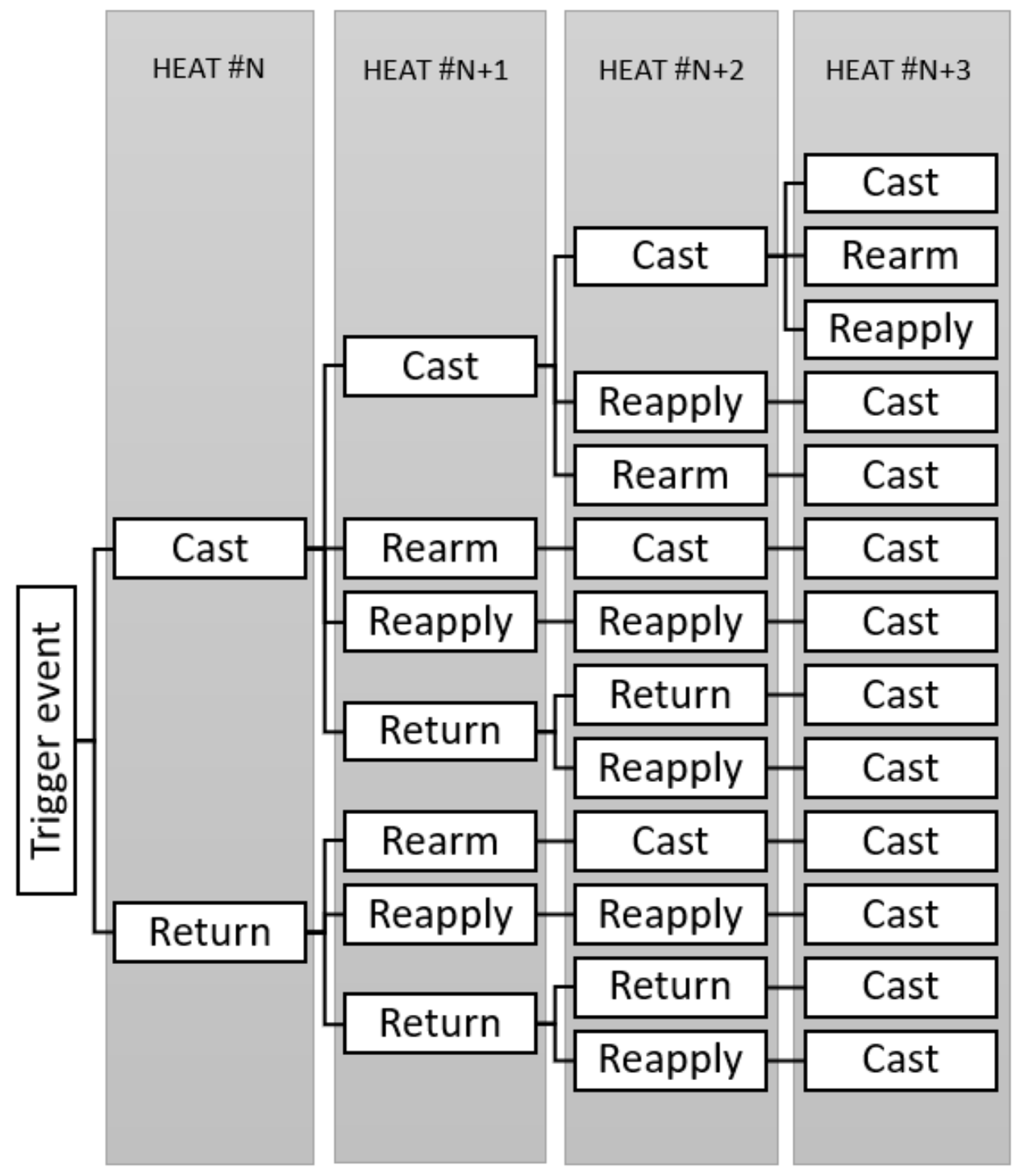

Figure 2. Decision Tree.

Some of these decisions are conditioned on the situation of the workshop, that is, availability of machines for maintenance, production or the committed order book. For an analysis of the four heats' posteriors to the trigger event, under these four previous options, there would be a total of 256 different situations to analyze in the workshop, that is, the tree decision would have a total of 256 branches. A series of restrictions or conditions for the validation of the various routes were added to the algorithm developed:

- Only one of the heats can have the rearm condition,

- After a rearm, the heats can only have the condition of cast

- The first heat, located in the continuous casting machine at the time of event $\mathrm{T}$, cannot have the condition of reapply or rearm.

The first two conditions focus on the central idea of any steel mill, which must be to avoid reset times/costs, while the third focuses on the physical constraints of the process: once a ladle has started pouring steel into the continuous casting machine, it can no longer be designated to any other destination. Finally, for four casts, from cast N, in which the 
trigger event takes place, to cast $N+3$, the algorithm's decision tree was reduced to the 13 assumptions, as seen in Figure 2.

To determine the optimal solution, the characteristics of the continuous casting process are considered. Each of the different branches of the decision tree represents a set of batch decisions, which allows a quick analysis of the processing times of each branch. Based on this, the algorithm construction process was carried out in four steps or stages.

STEP 1: Data Input. Definition of the instant $T$ in which the trigger event occurs, as well as the consequences and the situation of the workshop, introducing the necessary data in the algorithm.

In order to quantitatively analyze the different routes, the algorithm needs to know a series of parameters, relative to process variables of the steel plant, in addition to those that were already included in the original scheduling. These new parameters, necessary for the correct operation of the algorithm are:

- $\quad$ Time instant (T): time at which the line loss trigger event occurs, as previously defined.

- Heat number $(\mathrm{N})$ : position in the tundish where the heat is scheduled in the casting machine at the time of the line loss.

- Tundish warm-up time (Tqt): Time that the tundish of the following sequence has been heating up at time $\mathrm{T}$.

- $\quad$ Final casting time $(\mathrm{Tf} c \mathrm{~N}+\mathrm{i})$ : time required to finish the treatment in the continuous casting of the $\mathrm{N}+\mathrm{i}$ heat, where $\mathrm{I}=\{0,1,2,3,4, \ldots\}$.

- Load start time $(\mathrm{TckN}+\mathrm{i})$ : load start time in converters of the $\mathrm{N}+\mathrm{I}$ heat, where $\mathrm{I}=$ $\{0,1,2,3,4, \ldots\}$.

- Sequentially index $(\mathrm{Sn}+1)$ : this index is established between two consecutive heats and indicates whether a heat can be casted sequentially with the previous one without generating quality problems. $S=\{0.1\}$.

- Reapplicability Index (Rn): Indicates whether a heat can be reapplied to a different quality or not. $\mathrm{R}=\{0.1\}$.

- Active lines (L): number of active lines after the disruptive event.

This step is the only one that requires data feeding by the user. Apart from the instant of time $\mathrm{T}$ in hours in which the line loss event is triggered, the consequences of the event and the situation of the workshop are perfectly defined by introducing the following data:

- No. of heat in tundish. Indicates the position in the tundish of the heat that is being casted in the casting machine when the partial or total closure of the lines occurs. This heat is called heat $\mathrm{N}$.

- Total heats in tundish. Indicates the total number of heats scheduled in the current sequence. The algorithm defines the sequentially index between heats based on this number and the target quality for the steel grade of the sequence.

- Weight of ladle in T. Indicates the percentage of heat already processed at time T. It allows calculating the final casting time for the heat that is in process at time $\mathrm{T}$, that is, casting $\mathrm{N}$.

- Number of active lines after T (L). It indicates the number of active lines after the instant $\mathrm{T}$, which allows calculating the time it would take each of the subsequent heats to be processed in Continuous Casting.

- Quality of the tundish. Indicates the steel quality target of the current tundish.

- Quality of the next tundish. Indicates the steel quality objective of the following tundish. Indicates if two tundish are sequential with each other, and therefore the heats included in these.

- $\quad \mathrm{N}+1$ cast reapplicability. Indicates whether there is a possibility to adjust the composition of the $\mathrm{N}+1$ heat to the quality of the next scheduled tundish.

- $\quad \mathrm{N}+2$ cast reapplicability. Indicates whether there is a possibility to adjust the composition of the $\mathrm{N}+2$ heat to the quality of the next scheduled tundish.

- Tundish warm-up time. Indicates if the physical tundish for the next sequence has been set to preheat before instant $\mathrm{T}$, and in that case, how long it has been heating. 
STEP 2: The different sets of batch decisions are analyzed, represented by the branches of the decision-making tree, generating a finite number of alternative schedulings. In addition to the general algorithm constraints, the constraints defined by the shop situation apply, which have been intrinsically defined during Data Entry Step 1. In this way, if the closing of lines were complete $(\mathrm{L}=0)$, we would be in a breakdown situation, and continuing to cast heat $\mathrm{N}$ would be physically impossible, so all the solutions in which $\mathrm{N}$ heat is considered to have cast condition are removed. Similarly, a reapplicability index of 0 would prevent the decision to reapply the target heat.

When generating the multiple solutions, the algorithm advances through the branches of the decision tree, generating multiple results. Thus, in the decision to continue casting during the four casts involved, the time until the end of casting of the fourth ladle will be four times the casting time of a casting at the current speed, that is, with some line closed. If the decision were made to cast only the casting in the tundish, and then rearm, the next casts would be cast normally, which would result in the sum of one casting at the current speed (with closed lines) and three castings at the nominal speed of the machine. Unfortunately, to this second option, presumptively better than the first, it would be necessary to add the delay time for resetting the casting machine, so it will not always be the best option after all.

The machine reset time is set by process and is defined as the minimum time that elapses before a new tundish can be started. The continuous casting machine also needs a setup time in order to heat the nozzles to the target temperature. When sequencing two tundish, under normal conditions, the tundish that will follow in the sequence heats up while the previous one is still casting, overlapping the times and generating a minimum delay in rearming (reset time should be lower than the setup time in this case). However, in the event of a sequence break or unscheduled interruption, the tundish may not have started its warming cycle yet (reset time and setup time being the same, in this case). The algorithm used analyzes the tundish heating time when calculating the foreseeable rearm delay, which will be considered in the solutions that require it. Both the heating time and the remaining casting time according to rescheduling are considered to calculate the needed heating time, if any. In any case, a minimum delay will always be unavoidable, due to the need for a correct evacuation of the machine.

In the case of reapplying the heats, the change of casting machine is considered, and since both the tundish and the nozzles must also be heated, there is a situation similar to that of rearming, with the exception that in this case there is no minimum time to reset the machine, as you do not have to wait for the evacuation of the regarding hot metal. In this case, the setup time as already been accomplished, total or partially, when the trigger event takes place. Furthermore, the time remaining to finish casting the previous heats is not considered, as they are being casting in other machine, so it would eventually be possible to cast through both machines at the same time. However, changing the machine to take advantage of collision by reapplying it is not always possible, mainly due to differences in qualities, and it is the algorithm itself, based on the quality and reapplicability characteristics introduced in step 1, which makes sure that the option to reapply the castings exists, in which case it calculates the possible solutions on a regular basis. If a heat is not reapplicable, the algorithm would not return a solution for that branch of tree. Likewise, a tundish can never cast more casts than it is programmed for, so all solutions that involve casting too many casts will also be ignored.

During the algorithm's run through the multiple options of the tree, in those cases in which we find the need to return heats to the converter, either because they are not reapplicable, or because we find a total closure of the tundish lines, the algorithm calculates the delay it will take for the steel mill to recover the production of that melt. In other words, although the proposed solution needs to return the $n+1$ and $n+2$ casts, being able to advance the final casting time of the casting $n+3$, to this time a penalty for low productivity would be added, represented in the sum of the time required to cast the same amount of steel as that returned to converters. In any case, this penalty is considered to the 
nominal casting speed of the machine, and not to the one it had at the interruption point, which is significantly less than that which can be obtained after a reset.

With these premises, the algorithm is able to calculate the time it takes for a casting to be cast at the speed after the interruption, at the nominal speed of the casting machine, the machine reset time and the time necessary to reapply a casting, and also is able to calculate penalties for loss of production when returning heats to the converter and detecting some solutions incompatible with the current state of the workshop. Through the various branches of the decision-making tree, up to a maximum of 13 different solutions will be obtained for the casting end time of the casting $\mathrm{N}+3$, which is called TSP or Time to Standard Production. For comparison purposes, the algorithm also calculates the end-ofcasting time $\mathrm{N}+3$ from the moment of interruption, but assumes that it could continue working without rescheduling. This time is called TSPb (time to base standard production).

The formula for calculating the TSP is:

$$
\mathrm{TSP}=\mathrm{Tc} n+\operatorname{Tc} n+1+\operatorname{Tc} n+2+\operatorname{Tc} n+3+\operatorname{Trm}+\mathrm{Td},
$$

where $\operatorname{Tc} n$ is the casting time of heat $n$, Trm is the time necessary to reset the machine and start a new tundish and $\mathrm{Td}$ is the equivalent production time for the heat that has been necessary to return. All these notations and concepts can be seen defined in Table 1.

Table 1. Notation list.

\begin{tabular}{|c|c|}
\hline Notation & Meaning \\
\hline $\mathrm{T}$ & Time at which the line loss trigger event occurs. $\mathrm{T}=0$ for algorithm purposes \\
\hline Tcn & Time for completely cast heat $n$ at actual casting speed \\
\hline $\operatorname{Tr} n$ & $\begin{array}{l}\text { Time for completely cast heat } n \text {, at nominal speed (after rearm the casting } \\
\text { machine, or use the heat on other casting machine) }\end{array}$ \\
\hline Trm & Time necessary to reset the machine and start a new tundish \\
\hline $\operatorname{Td} n$ & $\begin{array}{l}\text { Equivalent time to produce the returned heat } n \text {, where } n=1,2,3 \text { or } 4 \text {, at } \\
\text { nominal speed }\end{array}$ \\
\hline Tfen & Time to finish the cast of heat $n$, where $n=1,2,3$ or 4 , from $T=0$. \\
\hline TSPi & $\begin{array}{l}\text { Time to reach standard production for the branch solution } \mathrm{I} \text {, where } \mathrm{I}=1,2 \text {. } \\
\text { 13. It is equivalent to } \mathrm{Tfc} 4 \text { for the I solution. }\end{array}$ \\
\hline $\mathrm{TSPb}$ & $\begin{array}{l}\text { Time to reach standard production for the standard solution of the } \\
\text { initial scheduling. }\end{array}$ \\
\hline
\end{tabular}

STEP 3: Comparison of the different sets of batch decisions obtained in step 2 applying a single evaluation criterion. This evaluation criterion can be economical, favoring the treatment of higher added value steel grades, or productive, looking to optimize workshop production. For this study, an evaluation criterion defined as time to standard production (TSP) was generated, which is defined as the time elapsed between the disrupting instant, or line loss $(\mathrm{T})$, and the final casting time $\mathrm{N}+3(\mathrm{TfcN}+3)$. This $\mathrm{N}+3$ casting was selected because it was considered the last one on which we can generate various actions in the decision tree (Figure 3). The $\mathrm{N}+4$ and later heats, due to the restrictions applied to the algorithm, will always have the cast condition, except for those that inherently in the initial scheduling had the reset condition.

Due to the characteristics of the decision tree, $\mathrm{N}+3$ casting will always be treated optimally in continuous casting machines, that is, with all the lines available, optimizing production, except in the case that it is decided to continue casting all scheduled heats and the number of remaining heats in the tundish is greater than three.

Table 2 shows the TSP of the different branches of the decision tree formulated, from which the 13 solutions that will be validated and compared are obtained: 
Table 2. TSP formulas for the branches of the decision tree.

\begin{tabular}{|c|c|c|c|c|c|c|c|}
\hline $\begin{array}{l}\text { Decision } \\
\text { Solutions }\end{array}$ & Heat $\mathbf{N}$ & Heat $N+1$ & Heat $N+2$ & Heat $N+3$ & $\begin{array}{l}\text { CCM Rearm } \\
\text { Time }\end{array}$ & $\begin{array}{c}\text { Returned Heat } \\
\text { Time }\end{array}$ & TSP \\
\hline Branch 1 & Cast & Cast & Cast & Cast & & & \\
\hline Solution 1 & Tc1 & Tc2 & Tc3 & Tc4 & - & - & $\mathrm{Tc} 1+\mathrm{Tc} 2+\mathrm{Tc} 3+\mathrm{Tc} 4$ \\
\hline Branch 2 & Cast & Cast & Cast & Rearm & & & \\
\hline Solution 2 & Tc1 & Tc2 & Tc3 & $\operatorname{Tr} 4$ & Trm & - & $\mathrm{Tc} 1+\mathrm{Tc} 2+\mathrm{Tc} 3+\operatorname{Tr} 4+\operatorname{Trm}$ \\
\hline Branch 3 & Cast & Cast & Tc3 & Reapply & & & \\
\hline Solution 3 & Tc1 & Tc2 & Tc3 & $\operatorname{Tr} 4$ & Trm & - & $\mathrm{Tc} 1+\mathrm{Tc} 2+\mathrm{Tc} 3+\operatorname{Tr} 4+\operatorname{Trm}$ \\
\hline Branch 4 & Cast & Cast & Reapply & Cast & & & \\
\hline Solution 4 & Tc1 & Tc2 & $\operatorname{Tr} 3$ & $\operatorname{Tr} 4$ & Trm & - & $\operatorname{Tc} 1+\operatorname{Tc} 2+\operatorname{Tr} 3+\operatorname{Tr} 4+\operatorname{Trm}$ \\
\hline Branch 5 & Cast & Cast & Rearm & Cast & & & \\
\hline Solution 5 & Tc1 & Tc2 & $\operatorname{Tr} 3$ & $\operatorname{Tr} 4$ & Trm & - & $\operatorname{Tc} 1+\operatorname{Tc} 2+\operatorname{Tr} 3+\operatorname{Tr} 4+\operatorname{Trm}$ \\
\hline Branch 6 & Cast & Rearm & Cast & Cast & & & \\
\hline Solution 6 & Tc1 & $\operatorname{Tr} 2$ & $\operatorname{Tr} 3$ & $\operatorname{Tr} 4$ & Trm & - & $\operatorname{Tc} 1+\operatorname{Tr} 2+\operatorname{Tr} 3+\operatorname{Tr} 4+\operatorname{Trm}$ \\
\hline Branch 7 & Cast & Reapply & Reapply & Cast & & & \\
\hline Solution 7 & Tc1 & $\operatorname{Tr} 2$ & $\operatorname{Tr} 3$ & $\operatorname{Tr} 4$ & Trm & - & $\operatorname{Tc} 1+\operatorname{Tr} 2+\operatorname{Tr} 3+\operatorname{Tr} 4+\operatorname{Trm}$ \\
\hline Branch 8 & Cast & Return & Return & Cast & & & \\
\hline Solution 8 & Tc1 & - & - & $\operatorname{Tr} 4$ & Trm & $\mathrm{Td} 2+\mathrm{Td} 3$ & $\operatorname{Tc} 1+\operatorname{Tr} 4+\operatorname{Trm}+\operatorname{Td} 2+\operatorname{Td} 3$ \\
\hline Branch 9 & Cast & Return & Reapply & Cast & & & \\
\hline Solution 9 & Tc1 & - & $\operatorname{Tr} 3$ & $\operatorname{Tr} 4$ & Trm & $\mathrm{Td} 2+\mathrm{Td} 3$ & $\operatorname{Tc} 1+\operatorname{Tr} 3+\operatorname{Tr} 4+\operatorname{Tr} m+\operatorname{Td} 2+\operatorname{Td} 3$ \\
\hline Branch 10 & Return & Rearm & Cast & Cast & & & \\
\hline Solution 10 & - & $\operatorname{Tr} 2$ & $\operatorname{Tr} 3$ & $\operatorname{Tr} 4$ & Trm & Td1 & $\operatorname{Tr} 2+\operatorname{Tr} 3+\operatorname{Tr} 4+\operatorname{Trm}+\operatorname{Td} 1$ \\
\hline Branch 11 & Return & Reapply & Reapply & Cast & & & \\
\hline Solution 11 & - & $\operatorname{Tr} 2$ & Tr3 & $\operatorname{Tr} 4$ & Trm & Td1 & $\operatorname{Tr} 2+\operatorname{Tr} 3+\operatorname{Tr} 4+\operatorname{Trm}+\operatorname{Td} 1$ \\
\hline Branch 12 & Return & Return & Return & Cast & & & \\
\hline Solution 12 & - & - & - & $\operatorname{Tr} 4$ & Trm & $\mathrm{Td} 1+\mathrm{Td} 2+\mathrm{Td} 3$ & $\operatorname{Tr} 4+\operatorname{Trm}+\operatorname{Td} 1+\operatorname{Td} 2+\operatorname{Td} 3$ \\
\hline Branch 13 & Return & Return & Reapply & Cast & & & \\
\hline Solution 13 & - & - & $\operatorname{Tr} 3$ & $\operatorname{Tr} 4$ & Trm & $\mathrm{Td} 1+\mathrm{Td} 2$ & $\operatorname{Tr} 3+\operatorname{Tr} 4+\operatorname{Trm}+\operatorname{Td} 1+\operatorname{Td} 2$ \\
\hline
\end{tabular}

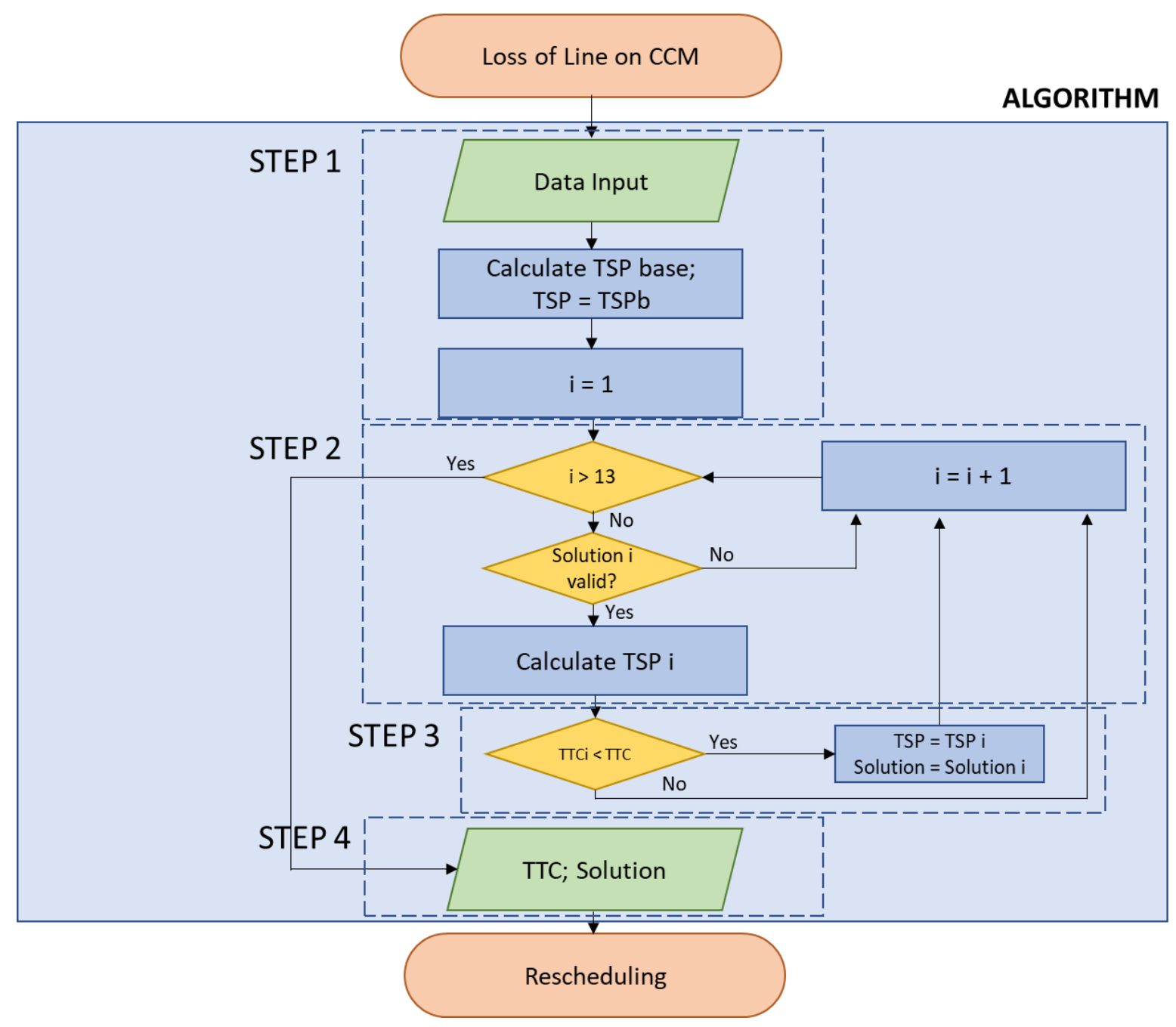

Figure 3. Algorithm flow chart. 
STEP 4: Selection of the most favorable option. The algorithm selects the most favorable branch of the decision-making tree, indicating the decisions to be made, which can be cast, return, rearm or reapply, heats $\mathrm{N}, \mathrm{N}+1, \mathrm{~N}+2$ and $\mathrm{N}+3$. The solution is presented in the form of a batch decision, that is: without scheduling the coordination of the castings in the relevant facilities. The original scheduling algorithm, once the changes indicated by the algorithm have been applied, will be able to generate its own scheduling decisions in order to optimize the operation of the workshop.

Figure 3 represents the flowchart of the algorithm, in which it is observed how the process begins with the loss of line and introduction of data in the algorithm, until the return of an optimal solution that we will implement in the MPS.

\section{Results}

This section first introduces the dataset and evaluation index. Then, it proves the effectiveness of the proposed method through the contrast experiment. Finally, a comparison is made between the experimental results and the state-of-the-art model.

\subsection{Dataset}

For the experimental evaluation and comparison of the validity of the algorithm, 500 random situations or representative experiments were generated, in which an event triggers a loss of one or more lines during the process. A typical steel plant was considered, consisting of two2 converters, two refining furnaces, one RH degasser station and two continuous castings, being each one different from the other. The main characteristics of the process were defined analogously to normal operation in a steel plant using the following premises:

- Each continuous casting machine was assumed to process 12 to 16 casts continuously and uninterruptedly. The two machines were considered capable of casting different types of steel, being incompatible with each other and obtaining from one of them billets as semi-products, with six casting lines, and blooms from the other, with three casting lines.

- $\quad$ Seven different classes of steels were considered, representing their families. Five of these classes come from the billet machine, each one having its own casting speed, according to the characteristics of the machine and the steel class itself. The remaining two families are obtained from the bloom machine, also representing a different width format, and therefore, also a different casting speed.

- A machine casting time was set for each heat; this varies depending on the quality of the product and the number of lines available. A maximum ladle time in tundish was also assumed to prevent cold steel closures.

- It was considered as a rule that a tundish is sequential with the previous one if the heats share the same quality and therefore can be cast consecutively without degradation of quality.

- It was also considered that a certain heat is reapplicable if its composition at time $\mathrm{T}$ is such that, by means of additions, a new steel composition compatible with a change in the objective of quality of the heat can be achieved.

- A stipulated fixed time was defined for machine reset, also considering that it takes time to warm up the tundish before starting any sequence. If the interruption occurs at the end of the sequence, the tundish warm-up will have already started.

Supplementary Materials shows the 500 random situations that have been carried out, trying to make this sample as complete as possible, including cases that cover different situations in the workshop and showing the data entered in the program during step 1. The generation of the 500 cases is made randomly, defining the following premises:

- No. of heats in tundish: Random number between 1 the total number of heats of the tundish.

- Total heats in tundish: Random number between 12 and 16, according to the normal operation of the steel mill. 
- Number of active lines after T (L): Random number between 0 and 2 for Bloom Tundish and between 0 and 5 for Billet Tundish.

- Weight of laddle in $\mathrm{T}(\mathrm{Tn})$ : The weight was considered as a random number between 5 (weight of a ladle at the end of the continuous casting phase and to be replaced by the next one) and 115 (weight of a ladle at the beginning of its continuous casting phase).

- Quality of the tundish: The different types of steel were numbered (7), and a random number between 0 and 7 was obtained to represent the quality of the tundish.

- Quality of the next tundish: The different types of steel were numbered (7), and a random number between 0 and 7 was obtained to represent the quality of the next tun-dish.

- $\quad \mathrm{N}+1$ heat reapplicability: Always Yes if the $\mathrm{N}$ heat is last of tundish (and therefore, the initial programming for this heat is maintained, regardless of the machine), otherwise Yes or No randomly.

- $\mathrm{N}+2$ heat reapplicability: Always Yes if the $\mathrm{N}+1$ heat is reapplicable or if the Heat $\mathrm{N}$ is the penultimate of the tundish. Otherwise, Yes or No randomly.

- Tundish warm-up time (min): If the $\mathrm{N}$ heat is before the last 3 of the tundish, 0 (warmup has not started yet). Otherwise, the number of remaining tundish casts after casting $\mathrm{N}$ is considered, plus the proportionate part of the cast $\mathrm{N}$ remaining to be cast (Weight of ladle in T), and the time is calculated as a function of of the nominal casting speed of the current tundish quality.

\subsection{Evaluation Criteria}

After obtaining the optimal solution by applying the algorithm, a direct comparison was made for each of the 500 cases with the solution obtained by applying the original scheduling method, after a standard rescheduling is carried out. As a result, a difference was obtained between the time to standard production (TSP) obtained from the algorithm and the TSP obtained in the plant in a conventional way, called TSPbase. This difference is called the time improvement index (TII) and is given in minutes. The improvement time is always considered between standard correction of the scheduling carried out in the plant, and the rescheduling proposed by the algorithm.

The results of the time improvement index for the billet machine grouped by steel class and by number of active lines after the disruptive event $(\mathrm{L})$ are shown in Table 3. Additionally, the number of simulations or tests carried out for each course is shown.

All the solutions granted by the algorithm have a positive TII, meaning this that every solution, at least, is as good as the standard one. This is easily checked, if the standard solution is one of the 13 considered by the algorithm in every situation. When TII is 0 , the algorithm has chosen the decision that fits with the standard one, producing no improvement in these cases, but also no losses.

Results of the TII for the bloom machine are shown on Table 4, grouped by steel class and number of active lines after T. This machine, as defined, has fewer lines, and it treats a lower quantity of steel classes, as it can be seen.

Comparing the data in Tables 3 and 4, an average time saving is obtained until reaching the standard production rate again on the billet machine of $28.13 \mathrm{~min}$, and on the bloom machine of 22.11. The total time-saving average, obtained by multiplying the partial means by the number of partial tests, adding them up and dividing by the total number of tests, is $26.41 \mathrm{~min}$, which represents a notable increase in production if the decision made by the algorithm is adopted. In addition, there are notable differences in the results obtained, mainly depending on the number of lines lost.

Table 5 shows the TII as a function of the number of active lines (L) after the line loss event, considering all the tests of the billet machine, without differentiating steel classes. The most alike results with traditional scheduling are those in which the uncertainty is fewer. For example, $\mathrm{L}=0$ means a complete shutdown of the machine, where the following castings could be only rearmed or reapplied, in addition to forcing the return of the $\mathrm{N}$ heat. This reduction of the possible paths to take in the decision tree is translated into a 
greater match when it comes to finding the optimal solution, rearm or reapply. Something similar occurs when $L=1$, because by considerably increasing the casting time, there is a risk that the steel will stay cold in the tundish, causing premature solidification and the closure of that last line. Due to this, the usual solution is to completely close the machine, avoiding continuing the sequence casting the rest of the tundish by a single line. On the opposite side, the loss of a single line $(\mathrm{L}=5)$, due to the high casting speed of the billet machine compared to other stations in the plant, hardly influences the rest of the process, so the solution from the original scheduling (continue casting), it is hardly improved by the algorithm.

Table 3. TII in billet casting machine, grouped according to steel classes and active lines.

\begin{tabular}{|c|c|c|c|}
\hline \multicolumn{4}{|c|}{ Billet Casting Machine } \\
\hline Steel Grade & $\mathbf{L}$ & TII (min) & Qty. Test \\
\hline \multirow{7}{*}{ FC800 } & 0 & 3.86 & 11 \\
\hline & 1 & 7.06 & 13 \\
\hline & 2 & 29.20 & 11 \\
\hline & 3 & 54.19 & 17 \\
\hline & 4 & 37.35 & 12 \\
\hline & 5 & 11.74 & 10 \\
\hline & Total & 26,25 & 74 \\
\hline \multirow{7}{*}{ HC650 } & 0 & 0.00 & 10 \\
\hline & 1 & 8.74 & 12 \\
\hline & 2 & 30.41 & 9 \\
\hline & 3 & 48.73 & 14 \\
\hline & 4 & 84.86 & 12 \\
\hline & 5 & 9.75 & 11 \\
\hline & Total & 32.15 & 68 \\
\hline \multirow{7}{*}{ PC480 } & 0 & 0.00 & 16 \\
\hline & 1 & 9.79 & 9 \\
\hline & 2 & 27.09 & 16 \\
\hline & 3 & 45.73 & 10 \\
\hline & 4 & 50.28 & 10 \\
\hline & 5 & 6.58 & 8 \\
\hline & Total & 22.23 & 69 \\
\hline \multirow{7}{*}{ PE325 } & 0 & 4.32 & 14 \\
\hline & 1 & 5.95 & 11 \\
\hline & 2 & 27.44 & 16 \\
\hline & 3 & 53.04 & 15 \\
\hline & 4 & 118.37 & 8 \\
\hline & 5 & 0.00 & 6 \\
\hline & Total & 32.96 & 70 \\
\hline \multirow{7}{*}{ PN156 } & 0 & 3.59 & 15 \\
\hline & 1 & 3.79 & 9 \\
\hline & 2 & 20.18 & 12 \\
\hline & 3 & 59.58 & 15 \\
\hline & 4 & 47.07 & 16 \\
\hline & 5 & 12.13 & 10 \\
\hline & Total & 27.25 & 77 \\
\hline casting machine & Total & 28.13 & 358 \\
\hline
\end{tabular}

When the number of lines after the disruptive event $(\mathrm{L})$ is three or four, or even two in some cases, the algorithm develops its greatest potential, mainly because the uncertainties are greater.

Regarding the analysis of the bloom machine, it can be seen in Table 4 that the width difference between steel grade formats in the assigned steel grades is translated into a significant variation in the results obtained. This is because while the algorithm works 
differentiating workshop situations and steel grades, the original scheduling treats both the same way, generating the same type of solutions without optimizing for both. Analogously to what happened with the billet machine, it is observed that for a complete strand closure $\mathrm{L}=0$, the improvements in the times are not remarkable, just as they are not significant for $\mathrm{L}=1$, even with the difference that can be seen between different formats. When $\mathrm{L}=2$, (equivalent to the billet machine casting by four lines) the algorithm takes advantage of the original scheduling.

Table 4. TII in bloom casting machine, grouped according to steel classes and active lines.

\begin{tabular}{cccc}
\hline \multicolumn{3}{c}{ Bloom Casting Machine } & \\
\hline Steel Grade & L & TII (min) & Qty. Test \\
\hline \multirow{2}{*}{ BG125 } & 0 & 2.74 & 22 \\
& 1 & 15.62 & 22 \\
& 2 & 34.60 & 34 \\
& Total & 20.26 & 78 \\
\hline \multirow{2}{*}{ BP235 } & 0 & 6.63 & 22 \\
& 1 & 8.47 & 22 \\
& 2 & 61.30 & 20 \\
\hline Bloom casting machine & Total & 24.35 & 64 \\
\hline
\end{tabular}

Table 5. TII in billet machine, grouped according to active lines.

\begin{tabular}{ccc}
\hline & Billet Casting Machine \\
\hline L & TII (min) & Qty. Test \\
\hline 0 & 2.37 & 66 \\
1 & 7.12 & 54 \\
2 & 26.71 & 64 \\
3 & 52.82 & 71 \\
4 & 63.27 & 58 \\
5 & 8.86 & 45 \\
Total & 28.13 & 358 \\
\hline
\end{tabular}

\section{Discussion}

The improvements shown in the previous tables demonstrate the validity of the designed algorithm, so it can be applied as a valid approach to the problem of continuous casting rescheduling, effectively combining batch and scheduling decisions in the same algorithm from the point of view of a situation that implies loose of lines in the caster and improving productivity. Some other approximations based on expertise tree decision may be carried, focusing on quality problems along the metallurgy phase, considering not only the productivity but the economic impact of not achieving the desired quality.

Most of the algorithms developed for improving the effectivity of a rescheduling in the continuous casting machine process are focused on obtained a quick response from the system, gaining agility when reprogramming all the tasks in the different stations [36], but none of them try to take advantage of reprogramming the batch decisions previously taken, changing only the MPS. Because of this, the algorithm proposed is a suitably tool for any steel plan, no matter which scheduling algorithm is used.

As for the main advantages of the algorithm, apart from the results showing the capacity of production increase, two of them must be highlighted: first, the algorithm is scalable and adaptable, being suitable for any steel plant, whichever machine distribution it has, only needing to redefine the tree decisions; and second, the algorithm has been designed to be used as a tool to be used at the same time as the main scheduling algorithm and only as a consulting tool, so the program could be installed easily in the steel plant, 
ensuring that no interference with the main program may occur. These two conditions make the algorithm suitable to be installed, adapted and used in any steel plant.

One of the main disadvantages of the proposed algorithm is that the changes proposed to improve production may affect the entire supply chain from the steel plant to the subsequent rolling system. This inconvenience can be avoided by increasing restrictions on the tree algorithm, as it is fully scalable and adaptable, in order to secure minimum requisites of production defined by the supply chain department. The more restrictions stated in the decisions tree, the less effective the algorithm will be, as the difference between the standard solution adopted in the plant will be closer to the one proposed.

To improve the effectiveness of the program, without the needed of increase the restrictions, future studies should focus on the relationship between the tree decision of the steel plant, and the batch decisions of the rolling plants.

\section{Conclusions}

In this paper, an effective rescheduling approach is developed for the CC rescheduling problem, based on improving productivity on the steel plant. When various disturbances occur, quickly and efficient adjusting the scheduling has high significance in order to ensure the production stability. Existing research methods study the scheduling decisions but it is difficult to guarantee the production without changing the casting plan. In this study, batch decisions are analysed and accordingly readjusted in order to minimize the time loses on the SC. A heuristic algorithm is developed in order to analyse the most important variables to be taken in account during the rescheduling decisions generating a high-quality solution for the problem.

Finally, comparisons with actual scheduling are conducted, showing the effectiveness of the developed algorithm as a tool that improves the TSP. Therefore, this algorithm could be applied as an effective approach to solve the SC rescheduling problem, focusing on minimising stoppage time.

The problem discussed is actual. The proposed algorithm for rescheduling the continuous casting production can be useful in a real steel plant. It may lead to improved production in a significant way, and eliminate uncertainty in decision-making, by objectively providing the best solutions to maximize production.

The data used for the development of the algorithm could be adapted to the different configurations of a real steel plant, as the program is adaptable and scalable.

Further works focus on rescheduling the original planning by studying the batch decisions in case of facing quality problems that derive in the loss of value of the heats that can lead to a decrease in productivity or the benefit.

Supplementary Materials: The following are available online at https:/ /www.mdpi.com/article/ 10.3390/app11156765/s1.

Author Contributions: Conceptualization, H.M.-P., E.P.V.-G. and V.R.-M.; Data curation, D.G.-M.; Formal analysis, H.M.-P., E.P.V.-G. and V.R.-M.; Investigation, D.G.-M. and H.M.-P.; Methodology, D.G.-M.; Resources, D.G.-M.; Supervision, H.M.-P., E.P.V.-G. and V.R.-M.; Validation, E.P.V.-G. and V.R.-M.; Visualization, E.P.V.-G. and V.R.-M.; Writing—original draft, D.G.-M.; Writing—review \& editing, H.M.-P. All authors have read and agreed to the published version of the manuscript.

Funding: This research received no external funding.

Institutional Review Board Statement: Not applicable.

Informed Consent Statement: Not applicable.

Data Availability Statement: All the data is available within the manuscript and the Supplementary Materials of the manuscript.

Conflicts of Interest: The authors declare no conflict of interest. 


\section{References}

1. Tang, L.X.; Liu, J.Y.; Rong, A.Y.; Yang, Z.H. A Review of Planning and Scheduling Systems and Methods for Integrated Steel Production. Eur. J. Oper. Res. 2001, 133, 1-20. [CrossRef]

2. Sun, L.; Liu, W.; Luh, P.B.; Chai, T.; Zheng, B. An Effective Approach for the Scheduling of Steel-Making and Continuous Casting System with Stochastic Processing Requirements. IFAC Proc. Vol. 2011, 44, 9500-9505. [CrossRef]

3. Sun, L.; Luan, F. Near Optimal Scheduling of Steel-Making and Continuous Casting Process Based on Charge Splitting Policy. IFAC Pap. 2015, 48, 1610-1615. [CrossRef]

4. Cui, H.; Luo, X. An Improved Lagrangian Relaxation Approach to Scheduling Steelmaking-Continuous Casting Process. Comput. Chem. Eng. 2017, 106, 133-146. [CrossRef]

5. $\quad$ Ballester, A.; Verdeja, L.; Sancho, J. Metalurgia Extractiva. Volumen 1: Fundamentos; Sintesis: Madrid, Spain, 2000; ISBN 978-84-7738802-9.

6. Heaslip, L.J.; McLean, A.; Sommerville, I.D.; Claims, T. Continuous Casting Vol 1-Chemical and Physical Interactions during Transfer Operations (Continuous Casting); Iron \& Steel Society of AIME: Warrendale, PA, USA, 1983; ISBN 978-0-89570-157-2.

7. Tang, L.; Wang, G. Decision Support System for the Batching Problems of Steelmaking and Continuous-Casting Production. Omega-Int. J. Manag. Sci. 2008, 36, 976-991. [CrossRef]

8. Chattopadhyay, K.; Isac, M.; Guthrie, R.I.L. Physical and Mathematical Modelling of Steelmaking Tundish Operations: A Review of the Last Decade (1999-2009). ISIJ Int. 2010, 50, 331-348. [CrossRef]

9. Pérez, M.A.; Mateos, P.; Calleja, J.M. El Proceso Siderúrgico; Arcelor: Avilés, Spain, 2007; Código Manual 1-03-1137.

10. Liu, J.; Fang, L. Steel-Making Process Scheduling Using Lagrangian Relaxation. Int. J. Prod. Res. 2002, 40, 55-70. [CrossRef]

11. Jiang, S.; Zheng, Z.; Liu, M. A Multi-Stage Dynamic Soft Scheduling Algorithm for the Uncertain Steelmaking-Continuous Casting Scheduling Problem. Appl. Soft Comput. 2017, 60, 722-736. [CrossRef]

12. Jiang, Z.; Yuan, S.; Ma, J.; Wang, Q. The Evolution of Production Scheduling from Industry 3.0 through Industry 4.0. Int. J. Prod. Res. 2021, 1-21. [CrossRef]

13. Lu, Y.; Xu, X.; Wang, L. Smart Manufacturing Process and System Automation-A Critical Review of the Standards and Envisioned Scenarios. J. Manuf. Syst. 2020, 56, 312-325. [CrossRef]

14. Chen, D.; Luh, P.B.; Thakur, L.S.; Moreno, J. Optimization-Based Manufacturing Scheduling with Multiple Resources, Setup Requirements, and Transfer Lots. Iie Trans. 2003, 35, 973-985. [CrossRef]

15. de Souza, M.C.; Gomes, A.C.; Bretas, A.M.C.; Ravetti, M.G. Models for Scheduling Charges in Continuous Casting: Application to a Brazilian Steel Plant. Optim. Lett. 2016, 10, 667-683. [CrossRef]

16. Schmidt, G. Scheduling with Limited Machine Availability. Eur. J. Oper. Res. 2000, 121, 1-15. [CrossRef]

17. Worapradya, K.; Thanakijkasem, P. Proactive Scheduling for Steelmaking-Continuous Casting Plant with Uncertain Machine Breakdown Using Distribution-Based Robustness and Decomposed Artificial Neural Network. Asia-Pac. J. Oper. Res. 2015, 32, 1550010. [CrossRef]

18. Vakhania, N.; Hernandez, J.A.; Werner, F. Scheduling Unrelated Machines with Two Types of Jobs. Int. J. Prod. Res. 2014, 52, 3793-3801. [CrossRef]

19. Tang, L.; Wang, G.; Chen, Z.-L. Integrated Charge Batching and Casting Width Selection at Baosteel. Oper. Res. 2014, 62, 772-787. [CrossRef]

20. Rossit, D.A.; Tohmé, F.; Frutos, M. Industry 4.0: Smart Scheduling. Int. J. Prod. Res. 2019, 57, 3802-3813. [CrossRef]

21. Ouelhadj, D.; Petrovic, S. A Survey of Dynamic Scheduling in Manufacturing Systems. J. Sched. 2008, 12, 417. [CrossRef]

22. Zandieh, M.; Gholami, M. An Immune Algorithm for Scheduling a Hybrid Flow Shop with Sequence-Dependent Setup Times and Machines with Random Breakdowns. Int. J. Prod. Res. 2009, 47, 6999-7027. [CrossRef]

23. Tang, L.; Liu, W.; Liu, J. A Neural Network Model and Algorithm for the Hybrid Flow Shop Scheduling Problemin a Dynamic Environment. J. Intell. Manuf. 2005, 16, 361-370. [CrossRef]

24. Long, J.; Zheng, Z.; Gao, X.; Pardalos, P.M. Scheduling a Realistic Hybrid Flow Shop with Stage Skipping and Adjustable Processing Time in Steel Plants. Appl. Soft Comput. 2018, 64, 536-549. [CrossRef]

25. Han, D.; Tang, Q.; Zhang, Z.; Li, Z. An Improved Migrating Birds Optimization Algorithm for a Hybrid Flow Shop Scheduling within Steel Plants. Mathematics 2020, 8, 1661. [CrossRef]

26. Sobottka, T.; Kamhuber, F.; Heinzl, B. Simulation-Based Multi-Criteria Optimization of Parallel Heat Treatment Furnaces at a Casting Manufacturer. J. Manuf. Mater. Process. 2020, 4, 94. [CrossRef]

27. Mourtzis, D.; Vlachou, E. A Cloud-Based Cyber-Physical System for Adaptive Shop-Floor Scheduling and Condition-Based Maintenance. J. Manuf. Syst. 2018, 47, 179-198. [CrossRef]

28. Li, J.; Pan, Q.; Mao, K. A Discrete Teaching-Learning-Based Optimisation Algorithm for Realistic Flowshop Rescheduling Problems. Eng. Appl. Artif. Intell. 2015, 37, 279-292. [CrossRef]

29. Huang, K.-W.; Wang, D.-W.; Du, B.; Yi, J. Modeling and Optimal Algorithm of Charge and Cast Scheduling of SteelmakingContinuous Casting. In Proceedings of the 2006 Chinese Control Conference, Harbin, China, 7-11 August 2006; pp. 1341-1345.

30. Ojstersek, R.; Lalic, D.; Buchmeister, B. A New Method for Mathematical and Simulation Modelling Interactivity: A Case Study in Flexible Job Shop Scheduling. Adv. Prod. Eng. Manag. 2019, 14, 435-448. [CrossRef]

31. Balog, M.; Dupláková, D.; Szilágyi, E.; Min, M.; Knapčíková, L. Optimization of Time Structures in Manufacturing Management by Using Scheduling Software Lekin. TEM J. 2016, 5, 319-323. [CrossRef] 
32. Missbauer, H.; Hauber, W.; Stadler, W. A Scheduling System for the Steelmaking-Continuous Casting Process. A Case Study from the Steel-Making Industry. Int. J. Prod. Res. 2009, 47, 4147-4172. [CrossRef]

33. Li, C.-L.; Zhong, W. Task Scheduling with Progress Control. IISE Trans. 2018, 50, 54-61. [CrossRef]

34. Hermann, M.; Pentek, T.; Otto, B. Design Principles for Industrie 4.0 Scenarios. In Proceedings of the 201649 th Hawaii International Conference on System Sciences (HICSS), Koloa, HI, USA, 5-8 January 2016; pp. 3928-3937.

35. Mourtzis, D. Adaptive Scheduling in the Era of Cloud Manufacturing. In Scheduling in Industry 4.0 and Cloud Manufacturing; Sokolov, B., Ivanov, D., Dolgui, A., Eds.; International Series in Operations Research \& Management Science; Springer International Publishing: Cham, Switzerland, 2020; pp. 61-85; ISBN 978-3-030-43177-8.

36. García-Menéndez, D.; Morán-Palacios, H.; Ortega-Fernández, F.; Díaz-Piloñeta, M. Scheduling in Continuous Steelmaking Casting: A Systematic Review. ISIJ Int. 2019. [CrossRef]

37. Pan, Q.; Wang, L.; Mao, K.; Zhao, J.; Zhang, M. An Effective Artificial Bee Colony Algorithm for a Real-World Hybrid Flowshop Problem in Steelmaking Process. IEEE Trans. Autom. Sci. Eng. 2013, 10, 307-322. [CrossRef]

38. Cowling, P.; Johansson, M. Using Real Time Information for Effective Dynamic Scheduling. Eur. J. Oper. Res. 2002, 139, 230-244. [CrossRef]

39. Jiang, S.-L.; Liu, M.; Lin, J.; Zhong, H. A Prediction-Based Online Soft Scheduling Algorithm for the Real-World SteelmakingContinuous Casting Production. Knowl. Based Syst. 2016, 111, 159-172. [CrossRef]

40. Yang, J.; Zhang, J.; Guan, M.; Hong, Y.; Gao, S.; Guo, W.; Liu, Q. Fine Description of Multi-Process Operation Behavior in Steelmaking-Continuous Casting Process by a Simulation Model with Crane Non-Collision Constraint. Metals 2019, 9, 1078. [CrossRef]

41. Ouelhadj, D.; Cowling, P.I.; Petrovic, S. Utility and Stability Measures for Agent-Based Dynamic Scheduling of Steel Continuous Casting. In Proceedings of the 2003 IEEE International Conference on Robotics and Automation (Cat. No.03CH37422), Taipei, Taiwan, 14-19 September 2003; Volume 1, pp. 175-180.

42. Kammammettu, S.; Li, Z. Multistage Adaptive Optimization for Steelmaking and Continuous Casting Scheduling under Processing Time Uncertainty. IFAC Pap. 2018, 51, 262-267. [CrossRef]

43. Pacciarelli, D.; Pranzo, M. Production Scheduling in a Steelmaking-Continuous Casting Plant. Comput. Chem. Eng. 2004, 28, 2823-2835. [CrossRef]

44. Li, J.; Duan, P.; Sang, H.; Wang, S.; Liu, Z.; Duan, P. An Efficient Optimization Algorithm for Resource-Constrained Steelmaking Scheduling Problems. IEEE Access 2018, 6, 33883-33894. [CrossRef]

45. Pang, X.; Gao, L.; Pan, Q.; Yu, S. Intelligent Rescheduling System for Steelmaking and Continuous Casting Production. In Proceedings of the 23rd International Conference on Industrial Engineering and Engineering Management 2016; Qi, E., Shen, J., Dou, R., Eds.; Atlantis Press: Amsterdam, The Netherlands, 2017; pp. 41-46.

46. Pinto, J.M.; Grossmann, I.E. Assignment and Sequencing Models for the Scheduling of Process Systems. Ann. Oper. Res. 1998, 81, 433-466. [CrossRef]

47. Framinan, J.M.; Fernandez-Viagas, V.; Perez-Gonzalez, P. Using Real-Time Information to Reschedule Jobs in a Flowshop with Variable Processing Times. Comput. Ind. Eng. 2019, 129, 113-125. [CrossRef]

48. Hou, D.; Li, T. Analysis of Random Disturbances on Shop Floor in Modern Steel Production Dynamic Environment. Procedia Eng. 2012, 29, 663-667. [CrossRef]

49. Pang, X.; Jiang, Y.; Yu, S.; Li, H.; Gao, L.; Che, Z. Flexible Job Shop Rescheduling Method of Steelmaking-Continuous Casting Base on Human-Computer Cooperation. CIMS 2018, 24, 2415-2427. [CrossRef]

50. Long, J.; Zheng, Z.; Gao, X.; Pardalos, P.M. A Hybrid Multi-Objective Evolutionary Algorithm Based on NSGA-II for Practical Scheduling with Release Times in Steel Plants. J. Oper. Res. Soc. 2016, 67, 1184-1199. [CrossRef]

51. Jiang, S.; Hao, J. A Two-Phase Soft Optimization Method for the Uncertain Scheduling Problem in the Steelmaking Industry. IEEE Trans. Syst. Man. Cybern. Syst. 2019, 47, 416-431. [CrossRef]

52. Mourtzis, D.; Gargallis, A.; Angelopoulos, J.; Panopoulos, N. An Adaptive Scheduling Method Based on Cloud Technology: A Structural Steelwork Industry Case Study. In Proceedings of the 5th International Conference on the Industry 4.0 Model for Advanced Manufacturing; Wang, L., Majstorovic, V.D., Mourtzis, D., Carpanzano, E., Moroni, G., Galantucci, L.M., Eds.; Springer International Publishing: Cham, Switzerland, 2020; pp. 1-14. 